instruments and experimerfting on the best methods of observation. A thorough test of the new Brashear doublet for stellar photography has been made by Hartmann's zonal method, and comparison photographs with different adjustments are given in illustration of the method.

Other work in this division included micrometric measurements of double stars, comet photographs, star occultations, solar photography, and adjustment of the new large grating spectrograph and cœlostat.

The cœlostat telescope is of the form installed by Hale at Mount Wilson, known as the Snow telescope, consisting of a plane mirror ccelostat with secondary mirror, concave image mirror, and Littrow spectrograph with plane diffraction grating. The main colostat mirror, 20 inches diameter, driven by clockwork, reflects the sunlight in a southerly direction to a secondary plane mirror, which in turn reflects the light northwards to a concave mirror, 18 inches diameter. This forms an image of the sun slightly less than 9 inches diameter on the slit plate of

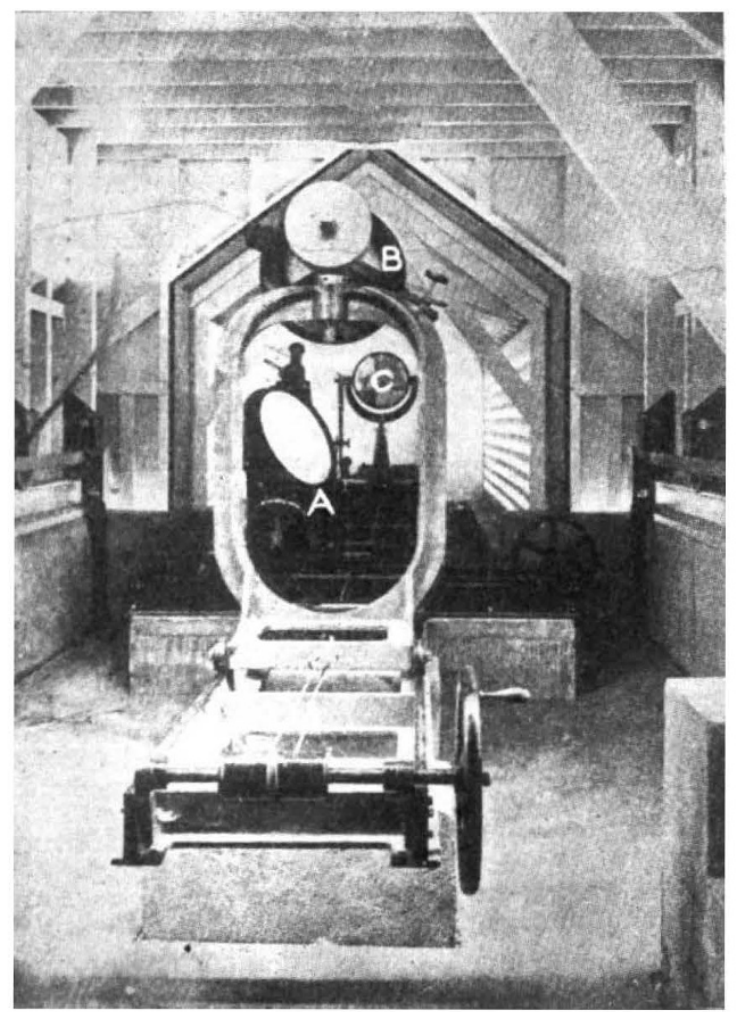

View of the Ottawa cœlostat, looking north. A, main cœlostat mirror ; $\mathrm{B}$, secondary colostat mirror; $\mathrm{C}$, concave image mirror.

the spectrograph, fixed in the basement of the main building of the observatory. This arrangement of mirrors is clearly shown in the accompanying illustration, taken from the report. The whole is covered by a louvred structure, part of which can be moved to allow of the sunlight reaching the cœlostat'mirror at all seasons.

The large solar spectrograph is located in the basement, and consists of a 6-inch lens of 22 feet ro inches focal length, together with a Michelson plane diffraction grating mounted in the Littrow form. The whole instrument is mounted so as to be capable of rotation about the collimation axis, this making it possible to place the slit tangential to any required point on the sun's limb.

Some interesting photographs of comet Morehouse are given showing the varying appearance presented by the tail during October and November, Igo8.

Geophysics.-In the geophysical division reports are presented showing the progress of determinations of seismology, terrestrial magnetism, gravity measurements, and latitude and longitude work on numerous station throughout the Dominion. Charles P. Butler.

\section{THE PRECIPITIN REACTION.}

THE precipitin reaction is also known as the "biological reaction " for proteins; it enables us to distinguish between proteins by using the animal body as a test-tube, and to establish differences between them which no other form of test-tube will detect. It is best known as a means for distinguishing human from other forms of blood. The procedure is briefly to inject an animal (usually a rabbit) repeatedly with a foreign protein; the serum of that animal then gives a precipitate with that protein, but with no other. So if the material injected is human blood, a precipitate is produced when the serum of the blood of the rabbit is added to human blood, or at any rate to the blood of the group of animals (the higher apes) to which man belongs, but not with any other sort of blood. The reaction is of value in forensic medicine, and it is also of value to the zoologist, as it enables him to demonstrate the blood-relationships of animals, and by the amount of precipitate to ascertain the degree of the relationship in figures.

A vast amount of research has centred around this discovery, Bordet, Uhlenhuth, Tchistowitch, and Nuttall being a few among the many who have devoted themselves to working out its details. A very clear and concise account of the principal facts has been recently published in a lecture given by Dr. W. A. Schmidt before the Cairo Scientific Society (Cairo Scientific Journal, November, I9II). Dr. Schmidt's name is known as one of those who have within recent years examined Egyptian mummies by chemical means, and his publications on the precipitin reaction have also been important. His lecture naturally deals with the question in a general and popular way, but includes a reference to some of his own work.

Among other interesting points, Dr. Schmidt has determined is the resistance of proteins to heat. It was formerly supposed that the "biological" property of proteins was easily destroyed by an elevated temperature, but Schmidt has shown that boiling for half an hour is necessary to abolish their power of reacting with a precipitin serum; and even although this is accomplished, the heated protein still retains the power when injected into an animal of inducing the formation of a precipitin which reacts with heated or boiled protein material. Further than this, protein may still be further " denaturalised" and retain a corresponding power; when, for instance, protein is coagulated by a high temperature, so that ordinary neutral reagents no longer dissolve it, a solution of it in dilute alkali will produce precipitin-formation in the blood of an injected animal, which will react only with the "denaturalised" protein used for the injection. This discovery extends the usefulness of the precipitin reaction, for with the precautions described by Dr. Schmidt it may be employed to detect proteins even though some of their principal chemical properties have been destroyed.

\section{SCIENTIFIC MEMORIAL VOLUME, CELE-}

BRATION OF THE 5OOTH ANNIVERSARY, UNIVERSITY OF ST. ANDREWS.

A NEATLY bound memorial volume of scientific papers was issued by the University of St. Andrews to mark, with other publications, its 5ooth anniversary last September, and is edited by Profs. McIntosh, Steggall, and Irvine. The first paper, on concrete representations of nonEuclidean geometry, by an able mathematician, Dr. D. M. Y. Somerville, consists of a description of the most important representations which have been devised for non-Euclidean geometry within the field of ordinary Euclidean geometry, viz. :-(r) the Cayley-Klein projective metric, or representation by straight lines referred to a conic as absolute; $(2)$ the conform representation by circles orthogonal to a fixed circle; (3) Beltrami's geodesic representation on surfaces of constant curvature; (4) McClintock and Johnson's representation by "visual geometry"; (5) the representation by a net of conics through two fixed points; and (6) Poincare's representation by diametral sections of a quadric surface.

The second paper is on the algebraic solution of in determinate cubic equations, by Mr. Robert Norrie. The third, by Prof. Peddie, treats of the problem of partition 
of energy, especially in radiation, with the author's usual ability, and the same may be said of the fifth paper, by the same skilful experimenter, on the deviations of the oscillations of a viscous solid from the isochronous law. Mr. J. P. Dalton gives a careful digest of the accuracy attainable with a modified form of Attwood's machine, whilst Mr. J. B. Ritchie further extends previous researches by Prof. Peddie on the dissipation of energy and other effects observed in torsional oscillation. The last of this series is an account of interesting experiments on wave impact on engineering structures, carried out by Prof. A. H. Gibson and Mr. W. N. Elgood, resulting in the conclusion that the effective internal pressure due to wave impact cannot exceed that exerted by wave impact on the face of a breakwater, and suggesting the provision of drains opening on the sheltered face.

The section devoted to chemistry contains a critical account of a new series of methylated sugars recently obtained in the Purdie Research Laboratory at St. Andrews by Prof. Irvine. The extended application of these researches is reviewed in an excellent paper by $\mathrm{Mr}$. C. R. Young, whilst Mr. W. S. Denham ably treats of new methods in the preparation of anhydrides of organic acids, and Mr. R. C. Wallace deals with the relationships of indium and thallium. These researches give an indication of the importance and variety of the work recently carried out in this department. Under the section of natural history and medicine, Prof. McIntosh gives a brief history of the chair of natural history at St. Andrews, and Prof. D'Arcy Thompson reprints his presidential address to the British Association, entitled "Magnalia Naturæ : or the Greater Problems of Biology.' The next paper is by Prof. E. E. Prince, dealing with the pioneer work in scientific fishery investigations at St. Andrews, and makes mention of many workers, now scattered in diverse regions, who have extended our knowledge of the department in a noteworthy manner, and by none more than the writer of the article. The last is a medical contribution on the important subject of the toxicity of local anæsthetics, by Prof. C. S. Marshall, who carried out a series of careful experiments with no fewer than eight drugs.

No zoological researches are included in the volume, since its scope was not understood until too late for the insertion of the able contributions of such well-known investigators as Dr. H. C. Williamson, Dr. H. M. Kyle, Dr. Wm. Nicoll, and many others whose names appear in the list of publications emanating from the Gatty Marine Laboratory.

\section{THE CONTROL OF INSECT PESTS IN} $C A N A D A$.

$\mathrm{A}^{\mathrm{T}}$ the meeting of the Manchester Literary and PhiloA sophical Society on January 9, Dr. C. Gordon Hewitt, Dominion entomologist, gave an account of the ravages of insect pests in Canada, and the means taken by the Dominion Government to combat them. The annual opening up of vast tracts of country, previously wild, destroys the balance of nature, and swarms of insects, finding fresh stores available, devastate the new growths. Some of these insects are of native origin, but are more frequently introduced. Thus the Hessian fly, Mayetiola destructor, Say, appeared in 1816 ; the wheat midge, Diplosis tritici, Kirby, in 1828 ; the chinch bug, Blissus leucopterus, Say, in 1866 ; and the Colorado potato-beetle, Leptinotarsa decemlineata, Say, in 1870. The larch sawfly, Lygaconematus erichsonii, Hartig, reached Canada in 1882 , and in a few years destroyed the mature larches over practically the whole of eastern Canada. The pear-leaf blister-mite, Eriophyes pyri, Nalepa, was first reported from Nova Scotia about 1887, and has since spread across Canada from the Atlantic to the Pacific.

Other pests referred to included the clover-root borer, Hylesinus trifolii, Müller; the warble-fly; the apple fruitminer, Argyresthia conjugella, Z.; the apple maggot, Rhagoletis pomonella, Walsh; and the San José scale, Aspidiotus perniciosus, Comst. It was found necessary to pass the San José Scale Act, prohibiting the importation of trees and nursery stock from countries in which the scale was known to exist; in Igor the restriction was removed, but infected plants were fumigated by prussic acid before admission. The brown-tail moth, Euproctis chrysorrhoea, L., has now reached Canada, and is attacking oak, elm, and maple, in addition to fruit trees. Contrary to expectations, the severe winters of Canada do not prove to be so fatal to the larvæ; experience has shown that some 30 per cent. survive after being frozen for two months in a block of ice. Attention is therefore being given to the parasites of this species; also the severely infested trees are sprayed to kill the young larvæ.

Dr. Hewitt gave an account of the precautionary measures taken and of legislation in the Dominion, and of the history of the Entomological Department there. Educational work is undertaken, and agriculturists and associations addressed on the means of prevention and control of outbreaks. At Ontario Agricultural College, and in other provinces, men are trained to act as assistants and inspectors in this branch.

\section{EXTERNAL" DEGREES AT THE UNIVERSITY OF LONDON.}

SIR WILliaM RAMSAY'S letter to Nature on the value of the "external" degrees of the University of London, published on February I (vol. 1xxxviii., p. 445), has given rise to a number of letters upon the subject. As several correspondents traverse the same ground, and limitations of space will not permit us to publish the letters in full, we subjoin a summary of the chief points raised.

Dr. A. D. Waller, F.R.S., thinks that no useful purpose would be served by any discussion of the particular case cited by Sir William Ramsay, where it is suggested an injustice has been done to a late student of University College, and proceeds to consider the principle involved. $\mathrm{He}$ urges that the great desideratum as regards the superior degrees of the University- " internal " as well as "external" -is not the abolition of the "external" degree, but publicity during examination of both kinds. A candidate presenting a doctoral thesis to the University is, says Dr. Waller, in the position of an investigator presenting a communication to a learned society, and ought to be called upon, or permitted, to expound and uphold his thesis by speech and by demonstration in the presence of the University. The "external " examinations ought not, he maintains, to be abolished, for they have been, and are, of far-reaching value as affording a guide to study and a standard of excellence throughout the Empire.

Prof. T. Johnson, of the Royal College of Science, Dublin, directs attention to the fact that the University of London was founded, in part, for students whom circumstances prevent from attendance at the London courses of instruction, and argues against the abolition of the " external", side in the University. He contends that the agitation for the conversion of the examining into a teachin university had its origin largely in the unpublished desire to safeguard certain vested interests. It was no uncommon thing in the old days, he says, for a professor in a London college to find his salary reduced owing to loss of fees caused by his replacement, at the end of his term of office as an examiner, by a provincial or other examiner. "This "anomaly" or 'injustice' was removed by the creation of the University's teaching side and intern examinerships."

Mr. W. J. Oakes, of the Oakes Institute, Walton, Liverpool, emphasises the similarity in the requirements, so far as the arts courses are concerned, for "internal" and "external" degrees, and attaches great importance to the fact that "external" candidates for science degrees must provide suitably attested evidence of practical training in a laboratory. He points out the comparatively small provision in provincial centres of scholarships to enable young men and women to attend day courses at local universities. He asks, "What are the young men who come from homes where the income is less than 20ol. a year to do?" If no other case could be made out for the "external" degree than that of the young men who cannot possibly attend the day classes of a university, this would, $\mathrm{Mr}$. Oakes says, outweigh all the arguments which can be advanced against it. 